\title{
超高感度オルトトルイジン試薬による 血糖の全血直接定量法の開発について*
}

\author{
高 原 喜八郎**
}

\section{Summary}

A new method was developed for the whole blood direct determination of blood sugar by an ultrahighly sensitive ortho-toluidine reagent (OT-37).

The sensitivity of OT-37 was 2.6 fold higher than the regular reagents. The procedure for the determination was as follows. $10 \mu \mathrm{l}$ of whole blood was mixed with $5 \mathrm{ml}$ of OT-37 by blowing out from a capillary pipette. The blood hemolyzed immediately on mixing. Absorbance at $565 \mathrm{~nm}(\mathrm{~Eb})$ was read and the tube was heated at $100^{\circ} \mathrm{C}$ for 3 minutes and 30 seconds. After cooling the tube in running water, absorbance at $565 \mathrm{~nm}(\mathrm{Ea})$ was read again. The difference between the two readings, $\Delta \mathrm{E}=\mathrm{Ea}-\mathrm{Eb}$, was found to be proportional to the glucose concentration.

In contrast with the negative interference caused by hemoglobin iron at the regular wave length of determination $(635 \mathrm{~nm})$, no interference was observed at $565 \mathrm{~nm}$. Addition of $10 \mu 1$ of $10 \mathrm{mg} / \mathrm{ml} \mathrm{gluta-}$ thione, either reduced or oxidized, gave no effect on readings. Positive interference caused by NAD or $\mathrm{NADH}$ was found to be cancelled by coexisting hemoglobin.

Recovery tests and comparison with the values obtained by conventional methods gave satisfactory results. nations.

The new method seemed, therefore, to be satisfactory and useful especially in emergency determi-

\section{は じめに}

今日, 血糖の臨床検査件数は日常検査項目中, 最も多 数を占めて扣り, その検査要求の出され方については緊 急検査と日常検査の 2 つの場合があり，また，定量原理 別としては還元法, 縮合法, 酵素法の 3 種に大別され, 各々の方法は用手法または自動化機器法として適用され ている. 自動化機器法は多数 (30件以上) の検体をると めて迅速に精度よく検査するのに適した方法であるが， 緊急的に発生する少数検体の迅速処理には，あまり有効 でないことは周知であり，この理由から例えばベックマ ンのグルコース分析計のような血清に分離した後, $10 \mu 1$ の試料として分析計に注入すると，約10秒後にグルコー ス值がデジタル表示されるような専用機が高価であるに もかかわらず緊急検査の要望に沿って使用されている. しかし，この場合でも試料は血清（漿）であるために採 血後血清分離までに数分の時間と遠心機を必要とするた
め，ベッドサイドや外来付近で検査を実施するにはやや 不便である. 従って, 血清に分離しない全血のまま直接 注入して血糖値がほぼ正確に，安価に測定でさる装置が あれば，より便利であろらことはいうまでもない，著者 はこのよらな装置に 乗せる目的で安価な反応系を探究 し, 実用に供され得ると思われる試薬と反応系を開発し て，全血直接法による血糖定量実験を行なったので，そ の成績について報告する。

\section{実験法および結果}

1. 装置・器具・試薬

1）日立 124 型分光光度計

2）日立 QPD 53 型記録計

3） 中外製薬ラピドブラッドアナライザー（RaBA）

4） グリンバム超微量自動ピペット

5）Drummond 毛細管定量ピペット

6) グルコース 標準液, 特級無水ブドウ糖を 100,

* Studies on a new whole blood direct method of the determination of blood sugar by an ultra highly sensitive ortho-toluidine reagent.

** Kihachiro Takahara, 神奈川県立衛生短期大学臨床化学教室. 
200，300，400 mg/dl になるように次の 2 種の溶媒 にて溶解した。

A）飽和安息香酸水溶液

B) Bovine albumin $6 \%$ 溶液 (溶媒 ; $1 / 2$ 飽和安息 香酸, $0.2 \% \mathrm{NaF}, 0.1 \% \mathrm{NaN}_{3}$ 含有)

7) 市販標準血清; Hyland normal.

8）プール血清; 自家製（用手法にてグルコース濃度 既知のもの)

\section{2. 発色試薬 (OT-37)}

佐々木匡秀によるオルトトルイジンホウ酸試薬（O-T $B$ 試楽 $)^{1-4)}$ を著者の研究により高感度に改良したものを 使用した. 本試楽は既報5-7) の如く $37^{\circ} \mathrm{C}$ においても発 色が進行し，定量に利用できるので OT-37 と呼称する. その調製法は次の如くである.

関東化学特級氷酢酸 $850 \mathrm{ml}$ を 11 の 3 角フラスコに入 れ，湯浴な.どで約 $70^{\circ} \mathrm{C}$ に加温する.この中に特級ホウ 酸 $6.80 \mathrm{~g}$ を入れ, 攪挥保温により完全に溶解させる. 約30分を要する. 次いで特級チ才尿素5.00 g を加え溶解 させる. 3 角フラスコを湯浴などよりとり出し, 流水中 で冷却後, 無色透明に精製したオルトトルイジン（和光 純薬） $150 \mathrm{ml}$ を加えよく覮找混和する.液温は上昇する から再び流水中で冷却後, 褐色びん中に入れ密栓し, 冷 暗所に保存する. 本試薬は調製後20日後までは感度やや 上昇するも以後安定となり, 数か月間の保存に耐学る.

OT-37 中には使用した氷酢酸中の微量 (約 $1 \%$ 以下) の水分以外の水は含んではならない。これ以上の水分混 入はグルコースの定量感度を大いに低下せしめる. これ は感度上昇を与えるホウ酸分子が溶液中で水相に移行し て，反応の場であるオルトトルイジン分子から遠ざかる ためであるらと考えられる.5)

\section{3. 実験操作}

$\mathrm{RaBA}$ 用試験管または $10 \mathrm{ml}$ 容小試験管に OT-37 を 自動分注器などにより $5.0 \mathrm{ml}$ ずつ分注し，グリンバム または毛細管ピペットなどにより，被検液 $10 \mu \mathrm{l}$ を正確 に注入混和する。被検液が全血の場合は毛細管ピペット により試楽中に完全に吹き达み，ひきつづき約10秒間空 気の吹き込及を続けながら毛細管自体で試薬内を攪找し 溶血を助子る.この場合，ピペット内を試薬で洗い込さ 操作をしてはならない，管壁の内側に残り付着している 血液が凝固して $5 \%$ 以上の負誤差となるからである. 被 検液注入後の反応管は約 3 分室温に放置してから RaBA または分光光度計にて加熱前の吸光度 $\mathrm{Eb}$ をむ。. 分光 光度計の波長は後述する理由から $565 \mathrm{~nm}$ にセットする が, 比較の目的から通常の $635 \mathrm{~nm}$ のよ夕記載してお く. RaBA の場合の波長は $540 \pm 10 \mathrm{~nm}$ の単一フィルタ
一より成っている.

次いで $\mathrm{Eb}$ をんだ反応管を沸騰している水浴中に浸 し, 正確に 3 分30秒加熱してただちに流水中に移して 3 分間水冷する. 再び上記の波長での吸光度をよみ $\mathrm{Ea}$ と する.

\section{4. 検量線}

上記の操作条件においては，グルコース標準液に飽和 安息香酸水溶液を用いる場合でも， $10 \mu 1$ の微量水分が $5 \mathrm{ml}$ の試薬中に混入する程度では試薬の感度は影響を 受けないから，標準液としては上記の6)-A）または B）のいずれを使用してもよい.むしろ 6)-A）功適当 であろら. 本法による感度を原法の佐々木 O-TB 試薬に よる感度と比較して検量線に示すと Fig. 1 の如くとな り，約 2.6 倍の感度上昇と直線性が認められた. 原法試 薬としては，市販グルコテスト (Glucotest, 中外) を使 用した。

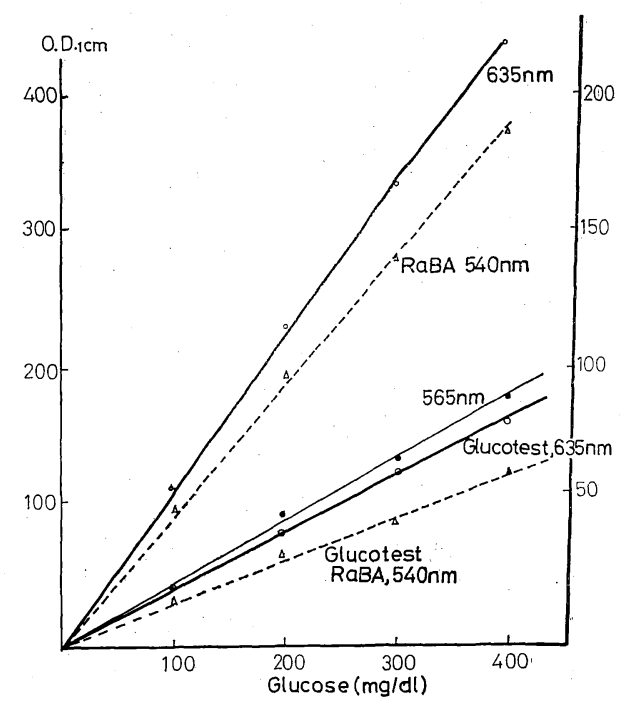

Fig. 1. Calibration curve for the determination of blood glucose by OT $-37,100^{\circ} \mathrm{C}$ procedure. $10 \mu \mathrm{l}$ of sample and $5 \mathrm{ml}$ of the reagent were used. Left ordinate is RaBA (Rapid Blood Analyzer, Chugai Seiyaku Ltd.) reding.

\section{5. 発色の安定性}

水泠後の色調の安定性を追跡すると Fig. 2 の如くと なり，約30分後までは安定であることが認められた。

6. 血球内諸物質の干涉について

本法のように超高感度化せしめたオルトトルイジンと グルコースの反応には, 血球内諸物質の干涉が懸念され る. そこで血球内物質として血色素 $(\mathrm{Hb})$ ，グルタチオ ン (GS), グルタチオン還元型 (GSH), NAD, NADH, 

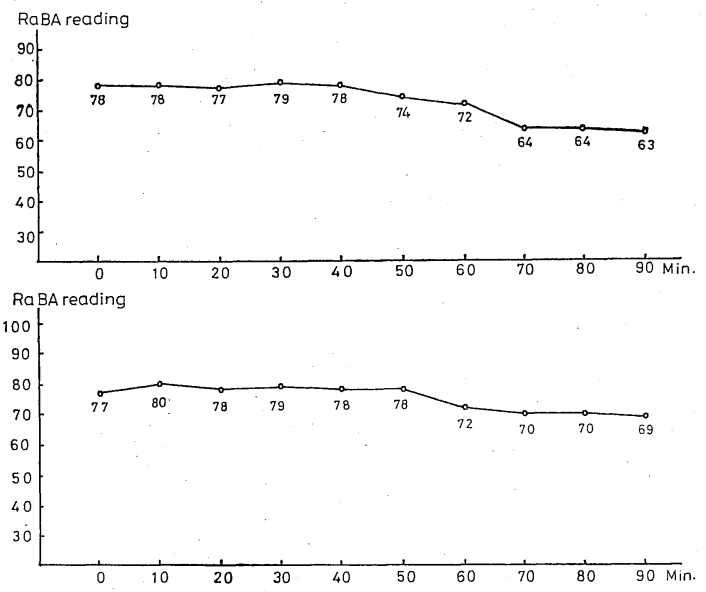

Fig. 2. Stability of coloration in the OT $-37,100^{\circ} \mathrm{C}$ procedure.

Top. : observation at $24^{\circ} \mathrm{C}$.

Bottom : observation at $31.5^{\circ} \mathrm{C}$.

$10 \mu \mathrm{l}$ of $200 \mathrm{mg} / \mathrm{dl}$ glucose solution was mixed with $5 \mathrm{ml}$ of the color reagent and heated for 3 minutes and 30 seconds at $100^{\circ} \mathrm{C}$ and cooled for 3 minutes.

RaBA readings were taken for the following 90 minutes.

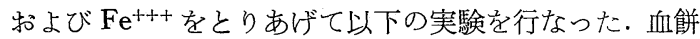
に水を加えて摫找溶血せしめ, 室温に数日放置してグル コースを消失せしめた $\mathrm{Hb}$ 水溶液 $(\mathrm{Hb}=5.5 \mathrm{~g} / \mathrm{dl}$, シアン メトへモグロビン法）をつくり，この $20,40,60,80 \mu 1$
を RaBA 用反応管にそれぞれ加え，さらに $200 \mathrm{mg} / \mathrm{dl}$ グ ルコース $10 \mu 1$ を各々へ追加注入しよくまぜる. RaBA による $\mathrm{Eb}, \mathrm{Ea}$ をよで $\mathrm{Hb}$ による $\mathrm{RaBA}$ 法への干涉を チェックした (Table 1, A 群).

RaBA の内藏固定フィルター $(540 \pm 10 \mathrm{~nm})$ による 成績では Table 1 に示すように $\mathrm{Hb}$ ゼロ（グルコース のみ) の $\mathrm{Ea}-\mathrm{Eb}=\Delta \mathrm{E}$ は 148 であり， $5.5 \% \mathrm{Hb}$ が20, $40,60,80 \mu 1$ と共存増加してゆくに従って $4 \mathrm{E}$ はそれぞ れ 165，181，198，209とプラスの干渉を示した。この 増加率を求めると，それぞれ $1.11,1.22,1.34,1.41$ の係数を得た。たまたま Table 1 に拉ける Ebの値につ いてみると，それぞれ 116，225，339，441 であり，偶 然これらの $\mathrm{Eb}$ の值の上 2 桁を小数点以下として, 1.00 に加えた数值（ここでは1.11，1.22，1.33，1.44）は上 記の係数に極めて近似していることが判明した。そこで $\mathrm{RaBA}$ の $\Delta \mathrm{E}$ 值を 1.[Eb]で割れば $\mathrm{Hb}$ にるプラスの 干涉が補正されるものと考光られ，以下の全血直接 RaBA 法值はすべてこの補正を行なった.

$\mathrm{Hb}$ 以外の GS, GSH, NAD, NADH については, それぞれの $10 \mathrm{mg} / \mathrm{ml}$ (全血中平均濃度の約 100 倍量), $\mathrm{Fe}^{+++}$については $10 \mathrm{mg} / \mathrm{dl}$ (全血中の $1 / 5$ 濃度) 水溶液 をつくり，各々の $10 \mu \mathrm{l}$ を, グルコース $200 \mathrm{mg} / \mathrm{dl}$ 液 10 $\mu 1$ を含む反応管に加えたB群と, さらにそれらにグル コースをゼロとした全血 $10 \mu \mathrm{l}$ を加えたC群をつくり実 験した。すなわら， B群は $\mathrm{Hb}$ と共存しない血球内物質 の干涉実験であり，C群は $\mathrm{Hb}$ と共存する上記物質の干

Table 1. Interference of $\mathrm{Hb}$ on the OT-37, $100^{\circ} \mathrm{C}$ reaction and a new correction formula for RaBA method.

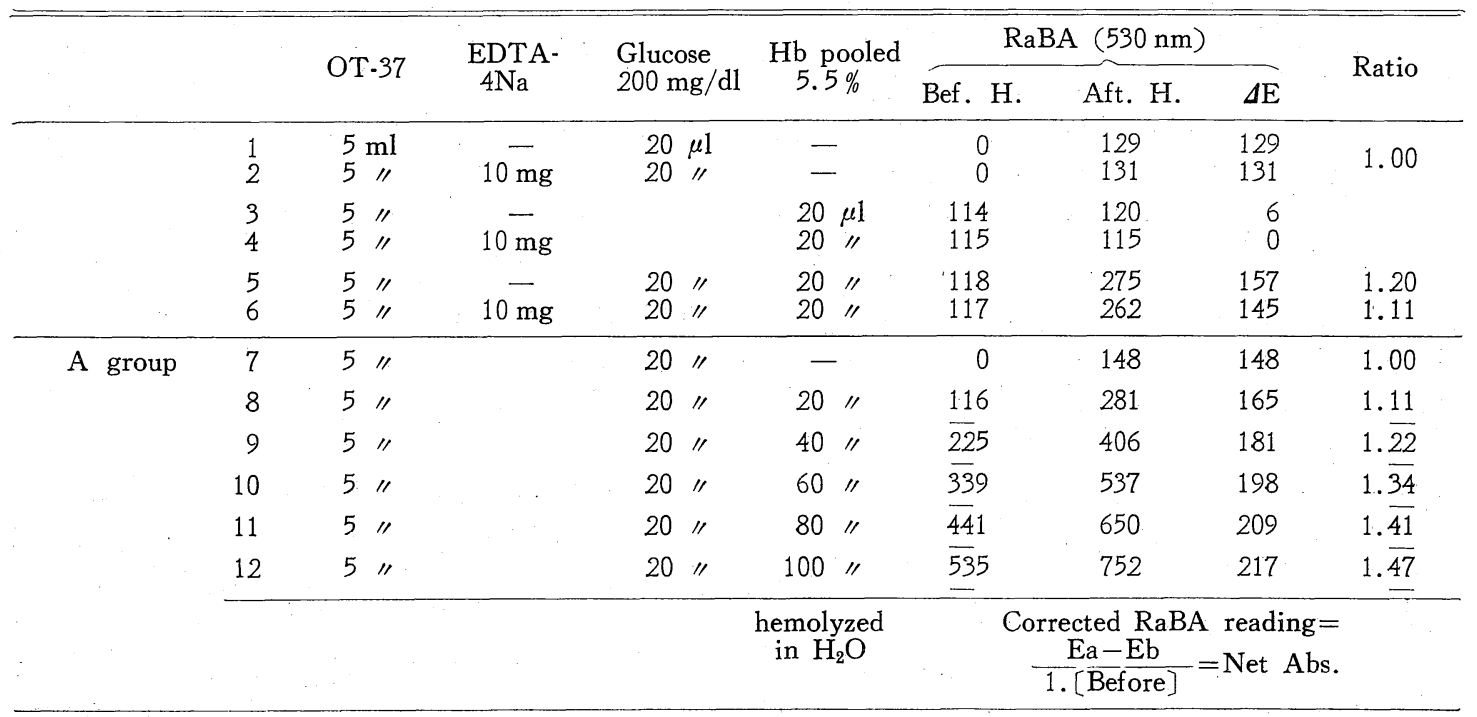


Table 2. Interference of intracellular substances on $\mathrm{OT}-37,100^{\circ} \mathrm{C}$ reaction.

\begin{tabular}{|c|c|c|c|c|c|c|c|c|c|c|c|c|c|c|}
\hline & & \multirow{2}{*}{$\begin{array}{l}\text { Name of } \\
\text { substance }\end{array}$} & \multicolumn{4}{|c|}{ RaBA (corrected) } & \multicolumn{4}{|c|}{$635 \mathrm{~nm}$} & \multicolumn{4}{|c|}{$565 \mathrm{~nm}$} \\
\hline & & & Bef. & Aft. & $\mathrm{mg} / \mathrm{dl}$ & 1 Recv. $\%$ & Bef. & Aft. & $\mathrm{mg} / \mathrm{dl}$ & Recv. \% & Bef. & Aft. & $\mathrm{mg} / \mathrm{dl}$ & Recv. $\%$ \\
\hline \multirow[t]{6}{*}{ B group } & 0 & - & 0 & 100 & 200 & & 0 & .230 & 200 & & 0 & 0.90 & 200 & \\
\hline & 1 & GS & 0 & 99 & & & 0 & .228 & & & 0 & 0.88 & & \\
\hline & 2 & GSH & 0 & 100 & & & 0 & .228 & & & 0 & 0.86 & & \\
\hline & 3 & NAD & 0 & 118 & $\uparrow$ & & 0 & .222 & $\downarrow$ & & 0 & 0.91 & & \\
\hline & 4 & NADH & 0 & 133 & $\uparrow \uparrow$ & & 0 & .235 & & & 0 & 1.05 & $\uparrow$ & \\
\hline & 5 & $\mathrm{Fe}^{+++}$ & 0 & 118 & $\uparrow$ & & 0 & .208 & $\downarrow \downarrow$ & & 0 & .093 & & \\
\hline \multirow[t]{6}{*}{ C group } & 0 & - & 0 & 98 & 200 & 100 & 0 & .230 & 200 & 100 & 0 & .090 & 200 & 100 \\
\hline & 1 & Blood & 181 & 310 & 227 & 113 & .088 & .282 & 167 & 83 & .099 & .192 & 205 & 102 \\
\hline & 2 & GS+Blood & 179 & 285 & 187 & 93 & .088 & .275 & 161 & 80 & .098 & .190 & 204 & 102 \\
\hline & 3 & $\mathrm{GSH}+1 /$ & 175 & 294 & 210 & 105 & .085 & .270 & 159 & 79 & .093 & .188 & 211 & 105 \\
\hline & 4 & $\mathrm{NAD}+" 1$ & 175 & 312 & 241 & 120 & .083 & .278 & 168 & 84 & .093 & .193 & 222 & 111 \\
\hline & 5 & $\mathrm{NADH}+" 1$ & 179 & 312 & 234 & 117 & .083 & .264 & 156 & 78 & .096 & .192 & 213 & 106 \\
\hline
\end{tabular}

EXP. OT $-37+$ Glucose $10 \mu \mathrm{l}(200 \mathrm{mg} / \mathrm{dl})+$ Subsce. $(10 \mathrm{mg} / \mathrm{ml})$.

Remarks: GS, Gultathione oxidized, $\mathrm{Fe}^{+++}-\left(\mathrm{FeCl}_{3}\right) 50 \mathrm{mg} / \mathrm{dl}$.

GSH, " reduced, Blood 4 days aged.

渉実験である.これらの結果を Table 2 に示す.

すなわち， $635 \mathrm{~nm}$ に拈いて有意の干涉を示すものは $\mathrm{Fe}^{++++゙ あ っ て マ イ ナ ス ~} 10 \%$ に及゙が $565 \mathrm{~nm}$ では大差 なくなった。

GS 括よび GSH はグルコース単独の場合には RaBA， $635 \mathrm{~nm}, 565 \mathrm{~nm}$ による測定値に対しては対照に比して 大なる差は与えない。しかし， $\mathrm{Hb}$ がさらに共存すると 大きなマイナス干渉を $635 \mathrm{~nm}$ 值に受けている.

$\mathrm{NAD}$ 扣よび NADH はグルコース単独の場合, RaBA 值に対しては 約 $20 \%$ のプス干渉を， $565 \mathrm{~nm}$ 值では NADH が $17 \%$ のプラス干渉を与えるようであるが 635 $\mathrm{nm}$ では大差を認めない. しかるに $\mathrm{Hb}$ が共存すると RaBA 值では約 $20 \%$ のフラス干涉を，635 nm 值では約 $20 \%$ のイナス干渉となり，565 nm 值では干渉は半減 するも, な和 6〜11\%のプラス干渉を残している. 従っ て, $565 \mathrm{~nm}$ 值に拈いてさえ, 正常量より 100 倍多量の $\mathrm{NAD}, \mathrm{NADH}$ が共存すると軽度のプラス干涉があり， また, 補正 RaBA 值でも大幅のプラス干渉から逃げられ ないようである。これは恐らくNADなどに含まれてい る $\mathrm{Fe}^{+++}$による影響であろらと思われ， $\mathrm{Fe}^{+++}$にる干 渉を,さらに，〈わしく検討するために，次の実験を行 なった。

すなわち，100，200，300，400 mg/dl のグルコース液 $10 \mu 1$ ずつを反応管にそれぞれ加壳てから， $50 \mathrm{mg} / \mathrm{dl}$ の $\mathrm{Fe}^{+++}$液 $\left(\mathrm{FeCl}_{3}\right)$ をさらに $10 \mu \mathrm{l}\left(\mathrm{Fe}^{+++}\right.$とし $\left.5 \mu \mathrm{g}\right)$ ず つ追加したもの ( $\mathrm{Fe}$ 群)と, 追加しないもの (対照群) について $100^{\circ} \mathrm{C}$ 加温発色させてから,これら8本の呈

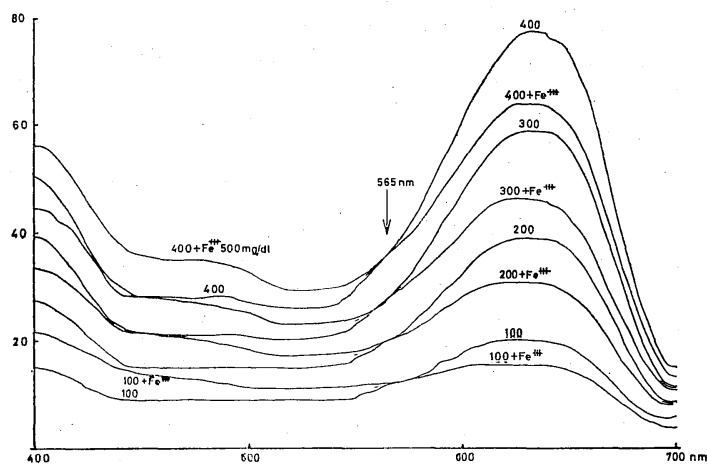

Fig. 3. Interference of ferric ion in the OT-37, $100^{\circ} \mathrm{C}$ procedure.

色液の吸收スペクトルを描記させたところ Fig. 3 の結 果を得た。すなわら $\mathrm{Fe}^{+++}$を含んだ呈色液は $635 \mathrm{~nm}$ に おいては対照群に比して，それぞれ約 $20 \%$ のイナス 干渉を受けるが， $565 \mathrm{~nm}$ に拈いては $\mathrm{Fe}^{+++}$の有無に関 せず両群は同一の吸光度を示し（交叉し）, $565 \mathrm{~nm}$ 以下 においては $\mathrm{Fe}$ 群は対照群に比してプラスの干渉を示す （例えば $530 \mathrm{~nm}$ に扣いては約 $+15 \%$ ) ことが認められ た。

$\mathrm{Fe}^{+++}$によるこれらの干渉は，実際には $\mathrm{Hb}$-鉄として も同様に作用するので，単に試薬中に EDTA などを加 えたのみでは $\mathrm{Hb}$-鉄の干涉からは逃げられない。従って 感度を約 $1 / 2$ に低下させても $565 \mathrm{~nm}$ に护ける吸光度を 利用することによって，はじめて Fe の干渉から完全に 逃げることができると思われる，感度の $1 / 2$ に低下する 
ことは，しかしながら OT-37 が従来の O-TB 試薬に比 して感度が 2.6 倍であることから，1/2 亿低下してもな お 1.3 倍の感度を保持しているので問題とはならない。

以上の成績から $\mathrm{Fe}^{+++}$が重大な干涉を与学る最大原 因であるらしいことが判明したが，な和 $565 \mathrm{~nm}$ に执い ても NADH またはNADによってプラスの干渉がやや 認められる理由については不明である。恐らく正常量の 100 倍の大量添加によるものか，あるいはNADなどの
存在下では交叉波長域のずれが起こるのか別個の検討を 要する問題であろうが，実際的にはあまり大なる影響で はない。

\section{7. 実験成績}

回収試験の成樍を. Table 3. K示す。:グルコースフリ 一血液 $10 \mu 1$ 共存下で 100 扰よび $200 \mathrm{mg} / \mathrm{dl}$ グルコース 液 $10 \mu \mathrm{l}$ 添加による 回収率は, 無補正 RaBA 值では 111 \%，108\%であるのに対して補正 RaBA 值では 99\%，93

Table 3. Recovery (\%) of the OT $-37,100^{\circ} \mathrm{C}$ reaction coexisting with blood.

\begin{tabular}{|c|c|c|c|c|c|c|c|c|c|c|c|c|}
\hline & \multirow{3}{*}{$\begin{array}{l}\text { ml of } \\
\text { OT-37 } \\
\text { added }\end{array}$} & \multirow{3}{*}{$\begin{array}{l}\text { Conc. of } \\
10 \mu 1 \text { glu- } \\
\text { cose added } \\
\mathrm{mg} / \mathrm{dl}\end{array}$} & \multirow{3}{*}{$\begin{array}{l}\mu 1 \text { of } \\
\text { blood } \\
\text { added }\end{array}$} & \multirow{3}{*}{$\begin{array}{l}\text { Value } \\
\text { expected } \\
\mathrm{mg} / \mathrm{dl}\end{array}$} & \multicolumn{8}{|c|}{ Value observed $(\mathrm{mg} / \mathrm{dl}) \&$ recovery $(\%)$} \\
\hline & & & & & & $\widehat{\mathrm{RaBA}}$ & $\mathrm{RaB}$ & & & $\mathrm{nm}$ & & $5 \mathrm{~nm}$ \\
\hline & & & & & Not corr & rected Rec. \% & Correcte & Rec. $\%$ & Obsd. & $\stackrel{\operatorname{Rec} .}{\%}$ & Obsd. & Rec. $\%$ \\
\hline 1 & 5 & 100 & - & 100 & & & & & & & & \\
\hline 2 & 5 & (Plasma) & 10 & (131) & 159 & & 130 & & 102 & & 135 & \\
\hline 3 & 5 & 100 & 10 & 100 & 111 & 111 & 99 & 99 & 70 & 70. & 102 & 102 \\
\hline 4 & 5 & 200 & 10 & 200 & 216 & 108 & 187 & 93 & 140 & 70 & 202 & 101 \\
\hline
\end{tabular}

Table 4. Glucose levels (mg/dl) obtained by the new method.

\begin{tabular}{|c|c|c|c|c|c|c|c|}
\hline \multirow{2}{*}{ No. } & \multicolumn{3}{|c|}{ Whole blood } & \multicolumn{4}{|c|}{ Plasma } \\
\hline & $\mathrm{RaBA}$ & $635 \mathrm{~nm}$ & $565 \mathrm{~nm}$ & $\mathrm{RaBA}$ & $635 \mathrm{~nm}$ & $565 \mathrm{~nm}$ & $\mathrm{AAI}^{*}$ \\
\hline 1 . & 190 & 141 & 174 & 220 & 187 & 192 & 187 \\
\hline 2 & 140 & 97 & 113 & 144 & 125 & 140 & 140 \\
\hline 3 & 211 & 154 & 211 & 232 & 195 & 200 & .200 \\
\hline 4 & 189 & 138 & 200 & 208 & 178 & 184 & 191 \\
\hline 5 & 134 & 92 & 132 & 108 & 93 & 100 & 106 \\
\hline 6 & 125 & 88 & 125 & 130 & 113 & 124 & 131 \\
\hline 7 & 101 & 70 & 80 & 96 & 85 & 77 & 94 \\
\hline 8 & 110 & 79 & 106 & 103 & 100 & 88 & 105 \\
\hline 9 & 105 & 75 & 106 & 105 & 95 & 88 & 102 \\
\hline 10 & 115 & 85 & 123 & 109 & 100 & 100 & 110 \\
\hline 11 & 108 & 92 & 117 & 119 & 108 & 106 & 111 \\
\hline 12 & 107 & 79 & 95 & 100 & 91 & 84 & 105 \\
\hline 13 & 162 & 119 & 153 & 192 & 172 & 160 & 178 \\
\hline 14 & 104 & 84 & 117 & 123 & 111 & 100 & 113 \\
\hline 15 & 112 & 79 & 112 & 123 & 113 & 106 & 118 \\
\hline 16 & 111 & 101 & 127 & 125 & 121 & 111 & 133 \\
\hline 17 & 149 & 108 & 127 & 155 & 143 & 137 & 154 \\
\hline 18 & 162 & 115 & 153 & 190 & 178 & 177 & 178 \\
\hline 19 & 114 & 87 & 122 & 101 & 95 & 90 & 112 \\
\hline 20 & 113 & 79 & 122 & 96 & 93 & 100 & 104 \\
\hline 21 & 112 & 83 & 122 & 100 & 97 & 100 & 111 \\
\hline 22 & 101 & 80 & 108 & 93 & 87 & 90 & 99 \\
\hline 23 & 109 & 79 & 122 & 100 & 93 & 95 & 124 \\
\hline 24 & 113 & 85 & 128 & 118 & 110 & 110 & 124 \\
\hline $\begin{array}{l}\text { Mean } \\
\text { Remarks }\end{array}$ & $\begin{array}{l}129 \\
\text { Correc }\end{array}$ & 95 & 129 & 133 & 120 & 119 & 130 \\
\hline
\end{tabular}

Color development; $100^{\circ} \mathrm{C}_{s}^{\Sigma} 3 / 30^{\prime \prime}$, cooling, $3^{\prime}$.

* Technicon Autoanalyzer, Basic Type, O-TB method. 


\section{（128）生物物理化学}

\%であったまた $635 \mathrm{~nm}$ 值では，いずれも $70 \%$ でマイ ナス $30 \%$ の渉が認められたが， $565 \mathrm{~nm}$ 值では $102 \%$, 101\%と最も良好な結果を得た。

Table 4 亿実際の全血試料拈よびそれぞれからの血漿

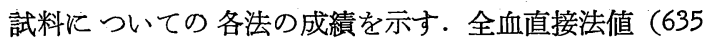
$\mathrm{nm}$ を除く)が血漿值と大差ないことが認められるよう である.

\section{総括および結論}

一応, 考慮される血球内諸物質と共存させたオルトト ルイジンーグルコース呈色反応の検討の結果，最も大き な干涉を与えるものは血色素鉄であるが，測定波長を $565 \mathrm{~nm}$ に兄らぶことによって，これらの干涉から逃れ 得ることを知った。また， RaBA 法の場合には血色素濃 度に依存する補正式を考案した。

OT-37 試薬自身に 対しては血色素自体は何んらの吸 光度増加をも加熱によって与えず，単なる下駄ばき効果 としての吸光度增加である. そして，これにグルコース が共存すれば，加熱によって特有の呈色調が追加される ので $\mathrm{Fe}^{+++}$の干涉のない $565 \mathrm{~nm}$ に和ける吸光度增加分 を測定することによって全血による血糖の直接定量法が 可能となった．この反応亲を利用することにより，專用 の血糖分析計の設計も可能となるものと思われる.

抒わりに，本研究に批いて，OT-37 が実現したのは
恩師宮本璋先生よりご指導賜わった水和水に関るす知見 に負う所が絶大であり，ここに特記して，嫨んで本研究 を故宮本璋先生の御霊前に捧げます（本研究の要旨は， 第20回日本臨床病理学会総会に执いて発表した).

\section{文献}

1）佐々木匡秀：オルトトルイジンーホウ酸法による 血糖超微量定量法, 臨床病理 12, 434 (1964).

2）玄番昭夫，他：O-Toluidine による血糖ならびに 血清（漿）糖定量法の追加検討 II, O-Toluidine 一段法に付帯する諸問題, 臨床病理 15, 580 (1967).

3）佐々木禎一：O-Toluidine-木ウ酸法による血糖の 迅速微量定量法, 臨床検查 11, 409 (1967).

4）佐々木禎一：O-Toluidine 用いる血糖の簡易定 量法, 臨床病理特集 15 号, 45〜54（1968）.

5）高原喜八郎，他：水を含まない新オルトトルイジ ン-ホウ酸試薬の開発と自動化学分析機への導入, 臨床検査 16, 524～528 (1972).

6）高原喜八郎, 他： $37^{\circ} \mathrm{C}$ 加温で発色する血糖定量 用新 O-TB試薬の開発とディスクリート式自動化 学分析機への導入について, 第 4 回臨床検査自動 化研究会記録, 15～18 (1973).

7) Kihachiro Takahara, et al.: Sensitive OToluidine Reagent for Glucose Assay at Moderately Elevated Temperatures, Microchem. J. 19, 319 (1974). 